\title{
Factors influencing antibiotic resistance burden in municipal wastewater treatment plants
}

\author{
Ana Novo • Célia M. Manaia
}

\begin{abstract}
Municipal wastewater treatment plants are recognized reservoirs of antibiotic-resistant bacteria. Three municipal wastewater treatment plants differing on the dimensions and bio-treatment processes were compared for the loads of amoxicillin-, tetracycline-, and ciprofloxacinresistant heterotrophic bacteria, enterobacteria, and enterococci in the raw inflow and in the treated effluents. The sewage received by each plant, in average, corresponded to 85,000 inhabitant equivalents (IE), including pretreated industrial effluents $(\leq 30 \%)$ in plant activated sludge, 105,000 IE, including pretreated hospital effluents $(\leq 15 \%)$ in plant trickling filter, and 2,000 IE, exclusively of domestic sewage, in plant submerged aerated filter. The presence of pretreated industrial effluents or of pretreated hospital sewage in the raw inflow did not imply significantly higher densities (per milliliter or per IE) of antibiotic-resistant bacteria in the raw wastewater. Longer hydraulic residence periods (24 h) corresponded to higher bacterial removal rates than shorter periods (12 and $9 \mathrm{~h}$ ), although such efficiency did not imply significant average decreases in the antibiotic resistance prevalence of the treated effluent. The bacterial loads in the treated effluent could be ranked according to the treatment efficiency, suggesting that the characteristics of the raw inflow may have less relevance on the quality of the treated wastewater than other aspects, such as the inflow volume, the type of biological treatment, or the hydraulic residence time.
\end{abstract}

Keywords Wastewater treatment - Antibiotic resistance. Amoxicillin · Tetracycline $\cdot$ Ciprofloxacin

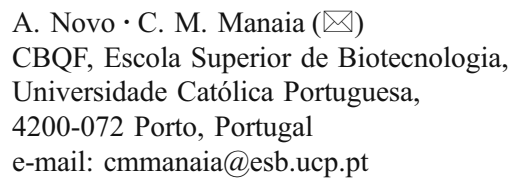

\section{Introduction}

Several studies on antimicrobial resistance in municipal wastewaters have contributed to include wastewater treatment plants among the leading reservoirs of antibiotic-resistant bacteria in the environment (Gallert et al. 2005; Ferreira da Silva et al. 2006, 2007; Goñi-Urriza et al. 2000; Baquero et al. 2008; Kümmerer 2009a, b; Martínez 2009; Servais and Passerat 2009). Human sewage comprises both antibioticresistant bacteria and antibiotic residues, a mixture that under favorable conditions, of high nutrient content and close contact between bacteria, may promote antibiotic resistance dissemination (Martínez 2009).

The loads of antibiotic-resistant bacteria in the raw and treated wastewater of municipal treatment plants suffer sharp variations from day to day, hampering clear-cut conclusions on the influence of wastewater treatment on the diminution or increase of antibiotic resistance prevalence (Guardabassi et al. 2002; Servais and Passerat 2009; Manaia et al. 2010). It has been referred that the input of antibiotic-resistant bacteria in the environment represents a major source of antibiotic resistance dissemination (Kümmerer 2009a; Martínez 2009). Considering this argument, high antibiotic-resistant bacteria loads in the raw inflow would be decisive for the spreading of antibiotic resistance by wastewater treatment plants. In summary, three major driving forces contributing for antibiotic resistance dissemination by wastewater treatment plants can be equated: (a) the presence of antibiotic-resistant bacteria in the raw inflow, with a possible dose-effect; (b) the variable efficiency of the wastewater treatment process on the removal of bacteria, namely, those harboring antibiotic resistance determinants; and (c) the potential increase or decrease of antibiotic resistance after wastewater treatment, which may differ among different bacterial and antibiotic resistance groups. 
In respect to (a), the higher the load of antibiotic-resistant bacteria in the raw wastewater, the more intense can be the burden of antibiotic resistance in the discharged effluent. For example, hospital wastewaters, which are supposed to contain higher loads of antibiotic-resistant organisms, represent relevant suppliers of resistance into the environment (e.g., Guardabassi et al. 2002; Blanch et al. 2003; Reinthaler et al. 2003; Baquero et al. 2008; Servais and Passerat 2009). In general, it can be hypothesized that municipal wastewater treatment plants receiving higher loads of antibiotic-resistant bacteria, for example, hospital-derived effluents, will have higher environmental burden in terms of antibiotic resistance spreading. This hypothesis was addressed in the current study. The efficiency of the wastewater treatment process on the removal of bacteria, referred to above (b), depends on several factors, namely, on the type of biological treatment and on the hydraulic residence time, as longer periods may favor antibiotic resistance genes exchange, or on the volume of wastewater treated per day (Tchobanoglous et al. 2003). Plants in which these aspects differed were compared in the current study in order to infer the possible implication on antibiotic resistance removal.

Concerning (c), it is known that wastewater treatment may impose rearrangements in bacterial populations and thus, antibiotic-resistant bacteria belonging to different taxonomic groups may be selected/eliminated differently during wastewater treatment (Vilanova et al. 2002; Forster et al. 2003; Tchobanoglous et al. 2003). On the other hand, the potential effect of selective pressure imposed by different antibiotics may vary according to its properties (as solubility, adsorption, degradability, etc.) and, thus, within a same group of bacteria, organisms tolerant to one drug may behave differently, during wastewater treatment, than others that are tolerant to another antimicrobial agent. In summary, the antibiotic resistance burden in the treated effluent is not necessarily the same for different antimicrobial drugs and for different bacterial groups. This issue was addressed in the current study.

To test the hypotheses referred to above, three municipal wastewater treatment plants that use different biological treatments (activated sludge (AS), trickling filter (TF), and submerged aerated filter (SAF); Table 1) were compared. Three resistance phenotypes against amoxicillin, tetracycline, and ciprofloxacin were selected - the first two were chosen because they are among the most prescribed, namely, in Portugal (Observatório Nacional de Saúde 2002), and the third because we observed that wastewater treatment could lead to an increase in resistance rates (Ferreira da Silva et al. 2006, 2007; Manaia et al. 2010). Residues of these antibiotics and others belonging to the same families (beta-lactams, tetracyclines, and fluoroquinolones) have been widely quantified in waste- and surface waters (Kim and Aga 2007; Kümmerer 2009b). Given the relevance that inflow bacteria may have on the spreading of antibiotic resistance, we selected three bacterial groups clearly associated with humans, with high environmental fitness and comprising very well known vectors of antibiotic resistance (www.earss.rivm.nl). Specifically, we intended to (1) assess the influence of the plant size, estimated on the bases of inhabitant equivalents and of the reception of pretreated hospital or industrial effluents on the load of antibiotic-resistant organisms reaching a municipal wastewater treatment plant; (2) estimate if, within the same plant, bacteria resistant to different antibiotics (or belonging to different groups) were removed at similar rates; and (3) compare the removal of antibiotic-resistant bacteria and assess if the loads of these bacteria in the treated outflow are directly proportional to those in the raw wastewater and/ or bacterial removal rates.

\section{Materials and methods}

Wastewater treatment plants and sampling

This study involved three municipal wastewater treatment plants with different dimensions and type of biological treatment (Table 1). In all the studied plants, the influent sewage undergoes a preliminary treatment to remove voluminous solids, but only plants AS and TF have a primary settling tank to remove the settleable solids. In plant AS, the settled sewage is biologically treated through an AS process. In the plants TF and SAF, the biological treatment occurs in fixed film reactors, constituted by a bed of a highly permeable matrix supporting a mixed population of microorganisms, which form a slime layer. The film reactors are a TF (in plant TF) and a submerged aerated filter, constituting approximately $50 \%$ of the volume of the biological tank (in plant SAF). The treated wastewater discharged from the secondary settling tank of the three plants enters a natural watercourse without previous disinfection. Plants AS and TF are located in different towns, where services represent the major activity, with industry occupying, respectively, $15.3 \%$ and $11.2 \%$ of the total urban area. Plant SAF is located in a touristic village, near the Atlantic coast, with $9.0 \%$ of urban area dedicated to industry and $6.5 \%$ to tourism (http://www.ine.pt).

Twenty-four-hour composite samples of the influent of the biological treatment tank, designated here as raw wastewater, and of final treated effluent (treated wastewater) were collected in glass sterile bottles $(1 \mathrm{~L})$, transported refrigerated to the lab, and analyzed within $12 \mathrm{~h}$. Samples were collected at independent sampling campaigns. In plants AS and TF, six samples were collected monthly, respectively, from February to May 2008 and from March to April of 2009, and from 
Table 1 Operational characteristics of wastewater treatment plants examined in this study

\begin{tabular}{|c|c|c|c|c|c|}
\hline \multicolumn{3}{|l|}{ WWTP } & AS & $\mathrm{TF}$ & SAF \\
\hline \multicolumn{3}{|c|}{ Type of sewage } & $\begin{array}{l}\text { Domestic }(\sim 70 \%) \text { and } \\
\text { pretreated industrial }(\sim 30 \%)\end{array}$ & $\begin{array}{l}\text { Domestic }(\sim 85 \%) \text { and } \\
\text { pretreated hospital }(\sim 15 \%)\end{array}$ & Domestic \\
\hline \multicolumn{3}{|c|}{ Biological treatment } & Activated sludge & Trickling filter & $\begin{array}{l}\text { Submerged } \\
\text { aerated filter }\end{array}$ \\
\hline \multicolumn{3}{|c|}{ Average daily flow ( $\mathrm{m}^{3} /$ day) } & 20,000 & 32,500 & 900 \\
\hline \multicolumn{3}{|c|}{ Hydraulic residence time (h) } & 12 & 9 & 24 \\
\hline \multicolumn{3}{|c|}{ Agglomeration population } & 100,000 & 150,000 & 8,700 \\
\hline \multicolumn{3}{|c|}{ Inhabitant equivalent } & 85,000 & 105,000 & 2,000 \\
\hline \multirow{2}{*}{\multicolumn{2}{|c|}{ Range of COD in WW $\left(\mathrm{mgO}_{2} / \mathrm{L}\right)^{\mathrm{a}}$}} & Raw & $553-604$ & $425-462$ & $107-800$ \\
\hline & & Treated & $67-124$ & $120-143$ & $92-187$ \\
\hline \multirow{2}{*}{\multicolumn{2}{|c|}{ Range of $\mathrm{BOD}_{5}$ in WW $\left(\mathrm{mgO}_{2} / \mathrm{L}\right)^{\mathrm{a}}$}} & Raw & $167-400$ & $247-312$ & $26-600$ \\
\hline & & Treated & $16-35$ & $38-40$ & $4-26$ \\
\hline \multirow{4}{*}{$\begin{array}{l}\text { Heavy metals } \\
\text { in } \mathrm{WW}^{\mathrm{b}}\end{array}$} & \multirow{2}{*}{$\begin{array}{l}\text { Arsenic (As) } \\
\quad(\mu \mathrm{g} / \mathrm{L})\end{array}$} & Raw & $1.8-2.4$ & $2.2-2.7$ & $2.7-3.5$ \\
\hline & & Treated & $1.3-1.8$ & $1.5-1.7$ & $1.9-2.4$ \\
\hline & \multirow{2}{*}{$\begin{array}{l}\text { Mercury }(\mathrm{Hg}) \\
\quad(\mu \mathrm{g} / \mathrm{L})\end{array}$} & Raw & $<0.10-0.46$ & $<0.10-0.18$ & $<0.10-0.15$ \\
\hline & & Treated & $<0.10-0.15$ & $<0.10-0.17$ & $<0.10$ \\
\hline \multicolumn{2}{|c|}{$\begin{array}{l}\text { Site of WWTP } \\
\text { discharge }\end{array}$} & & Water stream & $\begin{array}{l}\text { River, through a } \\
2-3 \mathrm{~km} \text { drain }\end{array}$ & $\begin{array}{l}\text { Water stream, } 500 \mathrm{~m} \\
\text { from the sea }\end{array}$ \\
\hline
\end{tabular}

March to May of 2008 and from April to June of 2009. In plant SAF, four samples were collected monthly from February and May of 2008.

Enumeration of total cultivable and antibiotic-resistant bacteria

Bacteriological analyses were performed using the membrane filtration method as described before (Ferreira da Silva et al. 2006; Manaia et al. 2010). Heterotrophic bacteria, enterobacteria, and enterococci were enumerated, respectively, on plate count agar (PCA, Pronadisa), mfecal coliforms (m-FC, Difco), and on m-enterococcus agar (m-Ent, Difco). The respective antibiotic-resistant subpopulations were enumerated on the same media supplemented with the following antibiotic concentrations: $32 \mathrm{mg} / \mathrm{L}$ amoxicillin, $16 \mathrm{mg} / \mathrm{L}$ tetracycline, or $4 \mathrm{mg} / \mathrm{L}$ ciprofloxacin. These antibiotic concentrations were determined in previous studies, as adequate to recover antibiotic-resistant bacteria (Watkinson et al. 2007), and we assume that bacteria growing in these media are resistant to the respective antibiotic, independently of the clinical resistance definition. Membranes, through which were filtered volumes of $1-10 \mathrm{~mL}$ of sample or of the adequate serial dilution, were placed onto the culture media and incubated for $24 \mathrm{~h}$ at $30^{\circ} \mathrm{C}$ (total heterotrophs) or $37^{\circ} \mathrm{C}$ (enterobacteria), or for $48 \mathrm{~h}$ at $37{ }^{\circ} \mathrm{C}$ (enterococci). All analyses were made in triplicate. After the incubation period, the number of colony forming units (CFU) was registered on the basis of filtering membranes containing between ten and 80 colonies. Values of CFU per milliliter obtained for each of the 12 culture media constituted the basis for the estimates indicated below.

Data analysis

The values of inhabitant equivalents were estimated for the time-period comprehending the sampling campaigns, on the basis of the definition of the Council Directive 91/271/EEC of 21 May 1991 concerning urban wastewater treatment, as equated below:

Inhabitant equivalent $=\frac{\operatorname{BOD} 5(\mathrm{~g} / \mathrm{L}) \times \text { daily flow }(\mathrm{L} / \text { day })}{60(\mathrm{~g} / \text { day })}$.

Antibiotic resistance percentage was estimated for each antibiotic in the raw and treated wastewater of each sampling as:

$\begin{aligned} \% \text { Resistance }= & \frac{(\mathrm{CFU} / \mathrm{mL}) \text { medium with antibiotic }}{(\mathrm{CFU} / \mathrm{mL}) \text { medium without antibiotic }} \\ & \times 100 .\end{aligned}$

The bacterial removal rate was estimated for each bacterial group: heterotrophs, enterobacteria, and enterococci, considering in each sampling campaign, the ratio between the 
CFU per milliliter observed, respectively, on PCA, on m$\mathrm{FC}$, or on $\mathrm{m}$-Ent in treated and in raw wastewater:

$\%$ Removal rate $=\left(1-\frac{(\mathrm{CFU} / \mathrm{mL}) \text { in treated wastewater }}{(\mathrm{CFU} / \mathrm{mL}) \text { in raw wastewater }}\right)$ $\times 100$

The loads of total and antibiotic-resistant bacteria expressed as CFU per day and per inhabitant equivalent were calculated for each sampling campaign as:

(CFU/day)/Inhab. Equiv.

$$
=\frac{\left[(\mathrm{CFU} / \mathrm{mL}) \times 10^{3} \times \text { daily flow }(\mathrm{L} / \text { day })\right]}{\text { Inhabitant equivalents }}
$$

Data on CFU per milliliter on each medium, resistance percentage in the raw and in the treated wastewater, bacterial removal rate of total and antibiotic-resistant bacteria, and resistant CFU per day per inhabitant equivalent were compared in and between the three plants through the analysis of variance and the post hoc test of Tukey (SPSS 16.0 for Windows).

\section{Results}

Raw wastewater: effect of the type of inflow and population served size

In this study, we examined three municipal wastewater treatment plants (Table 1), which are dimensioned to serve populations with different sizes. Our results suggest that neither the size of the agglomeration population nor of the inhabitant equivalents affects the density (CFU per milliliter) of heterotrophs and enterococci, antibiotic-resistant or not, found in the raw inflow, as the respective counts (CFU per milliliter) were in the same order of magnitude in the three plants. In contrast, enterobacteria presented significantly lower counts in plant TF than in the other plants $(p<0.001$; Table 2). The abundance of bacteria expressed as the counts of CFU per day per inhabitant equivalent gave a slightly different picture of the characteristics of the raw inflow (Fig. 1). In this respect, the most relevant difference was that in general, plant SAF received significantly more heterotrophic bacteria and enterococci $(p \leq 0.001)$. Among the three plants examined, TF receives pretreated hospital effluents in a percentage that ranges $15 \%$ of the total. It could be hypothesized that these pretreated effluents could contain higher loads of antibiotic-resistant bacteria and thus produce a noticeable effect on the quality of the raw inflow received in this plant. Nevertheless, no significantly higher loads of antibiotic-resistant bacteria were observed in the raw inflow of this plant (TF), when compared with others. In spite of this, the comparison of the prevalence of antibiotic resistance
(Table 3) leads to a different conclusion, as tetracycline resistance was observed to be more prevalent among heterotrophs and enterobacteria of the raw inflow of the TF plant $(p \leq 0.05)$. Similarly, ciprofloxacin resistance was more prevalent among enterococci of the influent of this plant $(p<$ 0.001). In summary, it is possible to conclude that although the numbers of antibiotic-resistant bacteria are not significantly higher in the TF plant, the received wastewater may contain higher percentages of bacteria able to grow in the presence of tetracycline or ciprofloxacin.

Comparative analysis of bacterial removal rates

The bacterial removal rates were compared for the three plants (Fig. 2), yielding average reductions of about $1.3 \mathrm{log}$ units of the CFU per milliliter in plant AS, of 0.6 in plant TF, and of 2.1 in plant SAF. As these values express, the plant SAF presented the highest efficiency, yielding higher removal bacterial rates $(p<0.001)$ with ranging values of $98.9-99.7 \%$ for every bacterial groups analyzed (heterotrophs, enterobacteria, and enterococci, total and antibiotic resistant). In plant AS, removal rates ranged $87.3-98.3 \%$, and no significant differences regarding the removal of total and antibiotic-resistant heterotrophs and enterobacteria $(p<0.1)$. In contrast, in this same plant, amoxicillin-resistant enterococci were removed with less efficiency than total or ciprofloxacin- or tetracycline-resistant enterococci $(p<$ 0.001 ). When compared with others, plant TF presented significantly lower bacterial removal rates, ranging 53.9$85.1 \%(p<0.001)$ and also higher heterogeneity on the removal of the different bacterial groups examined. In this plant, tetracycline-resistant organisms were among the groups which were removed more extensively that included also total and amoxicillin-resistant organisms $(p<0.05)$. Ciprofloxacin-resistant enterobacteria and enterococci were amongst the antibiotic resistance groups with lower removal rates, mainly when compared with tetracycline $(p<0.05)$.

When, within the same plant, the removal rates were compared for different bacterial groups (heterotrophs, enterobacteria, and enterococci), it was observed that wastewater treatment may have different implications depending on the antibiotic resistance group under analysis (Table 4). In plant AS, amoxicillin- and tetracycline-resistant enterobacteria were removed more efficiently than amoxicillin- or tetracycline-resistant heterotrophs $(p \leq 0.005)$. In this plant, amoxicillin-resistant enterococci were also removed at lower rates than the other bacterial groups $(p<0.001)$. In plant TF, total and tetracycline-resistant enterococci were removed more extensively than the other bacterial groups $(p<0.001$; $p<0.05$, respectively). Plant SAF, which presented the highest removal rates, removed total enterobacteria and enterococci more efficiently than heterotrophs $(p<0.001)$. However, this difference was not observed for ciprofloxacin- 
Table 2 Bacterial density (CFU per milliliter) of the different bacterial taxonomic and antibiotic resistance groups in the raw inflow and in the treated effluent

\begin{tabular}{|c|c|c|c|c|c|c|}
\hline \multirow[t]{2}{*}{ Bacteria group counts $(\mathrm{CFU} / \mathrm{mL})$} & \multirow[t]{2}{*}{ Resistance group } & \multirow[t]{2}{*}{ WWTP } & \multicolumn{2}{|l|}{ Raw wastewater } & \multicolumn{2}{|l|}{ Treated wastewater } \\
\hline & & & Range & Mean & Range & Mean \\
\hline \multirow[t]{12}{*}{ Heterotrophs } & \multirow[t]{3}{*}{ Total } & AS & $8.7 \times 10^{5}-5.5 \times 10^{6}$ & $2.9 \times 10^{6} \mathrm{a}$ & $6.0 \times 10^{4}-3.3 \times 10^{5}$ & $1.4 \times 10^{5} \mathrm{~b}$ \\
\hline & & $\mathrm{TF}$ & $1.0 \times 10^{6}-3.4 \times 10^{6}$ & $2.1 \times 10^{6} \mathrm{a}$ & $5.3 \times 10^{5}-2.6 \times 10^{6}$ & $9.9 \times 10^{5} \mathrm{c}$ \\
\hline & & SAF & $2.1 \times 10^{6}-4.8 \times 10^{6}$ & $3.0 \times 10^{6} \mathrm{a}$ & $1.4 \times 10^{4}-3.7 \times 10^{4}$ & $2.3 \times 10^{4} \mathrm{a}$ \\
\hline & \multirow[t]{3}{*}{ AML } & AS & $2.3 \times 10^{5}-1.2 \times 10^{6}$ & $6.4 \times 10^{5} \mathrm{a}$ & $5.8 \times 10^{3}-7.7 \times 10^{4}$ & $3.3 \times 10^{4} \mathrm{~b}$ \\
\hline & & $\mathrm{TF}$ & $2.0 \times 10^{5}-8.7 \times 10^{5}$ & $4.2 \times 10^{5} \mathrm{a}$ & $6.1 \times 10^{4}-6.2 \times 10^{5}$ & $2.3 \times 10^{5} \mathrm{c}$ \\
\hline & & SAF & $3.7 \times 10^{5}-7.9 \times 10^{5}$ & $6.0 \times 10^{5} \mathrm{a}$ & $2.8 \times 10^{3}-7.8 \times 10^{3}$ & $5.0 \times 10^{3} \mathrm{a}$ \\
\hline & \multirow[t]{3}{*}{ TET } & AS & $1.7 \times 10^{4}-4.5 \times 10^{4}$ & $3.0 \times 10^{4} \mathrm{a}$ & $4.0 \times 10^{2}-5.0 \times 10^{3}$ & $2.3 \times 10^{3} \mathrm{~b}$ \\
\hline & & $\mathrm{TF}$ & $2.0 \times 10^{4}-1.1 \times 10^{5}$ & $5.3 \times 10^{4} \mathrm{a}$ & $6.7 \times 10^{3}-1.8 \times 10^{4}$ & $1.0 \times 10^{4} \mathrm{c}$ \\
\hline & & SAF & $3.2 \times 10^{4}-8.0 \times 10^{4}$ & $5.1 \times 10^{4} \mathrm{a}$ & $1.6 \times 10^{2}-5.0 \times 10^{2}$ & $2.8 \times 10^{2} \mathrm{a}$ \\
\hline & \multirow[t]{3}{*}{ CIP } & AS & $1.8 \times 10^{4}-9.7 \times 10^{4}$ & $5.7 \times 10^{4} \mathrm{a}$ & $9.3 \times 10^{2}-7.4 \times 10^{3}$ & $3.9 \times 10^{3} \mathrm{~b}$ \\
\hline & & $\mathrm{TF}$ & $2.3 \times 10^{4}-1.5 \times 10^{5}$ & $5.3 \times 10^{4} \mathrm{a}$ & $6.3 \times 10^{3}-2.1 \times 10^{4}$ & $1.2 \times 10^{4} \mathrm{c}$ \\
\hline & & SAF & $3.8 \times 10^{4}-1.2 \times 10^{5}$ & $7.3 \times 10^{4} \mathrm{a}$ & $3.2 \times 10^{2}-9.0 \times 10^{2}$ & $5.8 \times 10^{2} \mathrm{a}$ \\
\hline \multirow[t]{12}{*}{ Enterobacteria } & \multirow[t]{3}{*}{ Total } & AS & $8.2 \times 10^{5}-3.4 \times 10^{6}$ & $1.7 \times 10^{6} \mathrm{~b}$ & $2.0 \times 10^{4}-2.3 \times 10^{5}$ & $7.1 \times 10^{4} \mathrm{~b}$ \\
\hline & & $\mathrm{TF}$ & $3.1 \times 10^{5}-1.3 \times 10^{6}$ & $6.4 \times 10^{5} \mathrm{a}$ & $1.1 \times 10^{5}-2.6 \times 10^{5}$ & $2.0 \times 10^{5} \mathrm{c}$ \\
\hline & & SAF & $8.4 \times 10^{5}-1.8 \times 10^{6}$ & $1.5 \times 10^{6} \mathrm{~b}$ & $1.7 \times 10^{3}-9.5 \times 10^{3}$ & $5.1 \times 10^{3} \mathrm{a}$ \\
\hline & \multirow[t]{3}{*}{ AML } & AS & $4.5 \times 10^{5}-2.0 \times 10^{6}$ & $9.9 \times 10^{5} \mathrm{~b}$ & $3.7 \times 10^{3}-5.1 \times 10^{4}$ & $1.7 \times 10^{4} \mathrm{~b}$ \\
\hline & & $\mathrm{TF}$ & $2.3 \times 10^{5}-6.8 \times 10^{5}$ & $4.2 \times 10^{5} \mathrm{a}$ & $6.6 \times 10^{4}-1.2 \times 10^{5}$ & $8.9 \times 10^{4} \mathrm{c}$ \\
\hline & & SAF & $6.4 \times 10^{5}-1.3 \times 10^{6}$ & $8.6 \times 10^{5} \mathrm{~b}$ & $1.1 \times 10^{3}-3.3 \times 10^{3}$ & $2.3 \times 10^{3} \mathrm{a}$ \\
\hline & \multirow[t]{3}{*}{ TET } & AS & $2.4 \times 10^{4}-1.5 \times 10^{5}$ & $6.5 \times 10^{4} \mathrm{a}$ & $5.0 \times 10^{2}-3.3 \times 10^{3}$ & $1.8 \times 10^{3} \mathrm{~b}$ \\
\hline & & $\mathrm{TF}$ & $1.2 \times 10^{4}-1.8 \times 10^{5}$ & $6.2 \times 10^{4} \mathrm{a}$ & $4.5 \times 10^{3}-8.6 \times 10^{3}$ & $5.8 \times 10^{3 \mathrm{c}}$ \\
\hline & & SAF & $2.9 \times 10^{4}-6.8 \times 10^{4}$ & $4.4 \times 10^{4} \mathrm{a}$ & $6.9 \times 10^{1}-1.9 \times 10^{2}$ & $1.2 \times 10^{2} \mathrm{a}$ \\
\hline & \multirow[t]{3}{*}{ CIP } & AS & $5.6 \times 10^{3}-7.5 \times 10^{4}$ & $3.1 \times 10^{4} \mathrm{~b}$ & $3.0 \times 10^{2}-2.4 \times 10^{3}$ & $1.0 \times 10^{3} \mathrm{~b}$ \\
\hline & & $\mathrm{TF}$ & $1.9 \times 10^{3}-1.8 \times 10^{4}$ & $8.5 \times 10^{3} \mathrm{a}$ & $1.3 \times 10^{3}-3.1 \times 10^{3}$ & $1.9 \times 10^{3} \mathrm{c}$ \\
\hline & & SAF & $7.3 \times 10^{3}-4.4 \times 10^{4}$ & $2.5 \times 10^{4} \mathrm{~b}$ & $5.6 \times 10^{1}-2.3 \times 10^{2}$ & $1.0 \times 10^{2} \mathrm{a}$ \\
\hline \multirow[t]{12}{*}{ Enterococci } & \multirow[t]{3}{*}{ Total } & AS & $8.3 \times 10^{3}-2.6 \times 10^{4}$ & $1.9 \times 10^{4} \mathrm{a}$ & $5.3 \times 10^{2}-2.3 \times 10^{3}$ & $1.0 \times 10^{3} \mathrm{~b}$ \\
\hline & & $\mathrm{TF}$ & $7.4 \times 10^{3}-2.9 \times 10^{4}$ & $1.6 \times 10^{4} \mathrm{a}$ & $1.5 \times 10^{3}-6.1 \times 10^{3}$ & $3.5 \times 10^{3} \mathrm{c}$ \\
\hline & & SAF & $1.3 \times 10^{4}-1.7 \times 10^{4}$ & $1.6 \times 10^{4} \mathrm{a}$ & $2.7 \times 10^{1}-5.8 \times 10^{1}$ & $4.3 \times 10^{1} \mathrm{a}$ \\
\hline & \multirow[t]{3}{*}{ AML } & AS & $5.3 \times 10^{1}-1.2 \times 10^{2}$ & $8.4 \times 10^{1} \mathrm{a}$ & $5.3 \times 10^{0}-1.8 \times 10^{1}$ & $8.8 \times 10^{0} \mathrm{a}$ \\
\hline & & $\mathrm{TF}$ & $1.6 \times 10^{1}-8.8 \times 10^{1}$ & $6.3 \times 10^{1} \mathrm{a}$ & $1.3 \times 10^{0}-4.3 \times 10^{1}$ & $2.0 \times 10^{1} \mathrm{a}$ \\
\hline & & SAF & $<1.0 \times 10^{0}$ & $<1.0 \times 10^{0}$ & $<1.0 \times 10^{0}$ & $<1.0 \times 10^{0}$ \\
\hline & \multirow[t]{3}{*}{ TET } & AS & $2.1 \times 10^{3}-3.6 \times 10^{3}$ & $3.2 \times 10^{3} \mathrm{a}$ & $1.1 \times 10^{2}-2.7 \times 10^{2}$ & $2.0 \times 10^{2} \mathrm{~b}$ \\
\hline & & $\mathrm{TF}$ & $1.9 \times 10^{3}-5.5 \times 10^{3}$ & $3.4 \times 10^{3} \mathrm{a}$ & $6.8 \times 10^{1}-1.1 \times 10^{3}$ & $4.7 \times 10^{2} \mathrm{~b}$ \\
\hline & & SAF & $2.0 \times 10^{3}-4.5 \times 10^{3}$ & $3.4 \times 10^{3} \mathrm{a}$ & $3.8 \times 10^{0}-1.2 \times 10^{1}$ & $1.0 \times 10^{1} \mathrm{a}$ \\
\hline & \multirow[t]{3}{*}{ CIP } & AS & $1.6 \times 10^{2}-5.7 \times 10^{2}$ & $3.1 \times 10^{2} \mathrm{~b}$ & $1.4 \times 10^{1}-3.7 \times 10^{1}$ & $2.1 \times 10^{1} \mathrm{a}$ \\
\hline & & $\mathrm{TF}$ & $1.5 \times 10^{2}-1.7 \times 10^{3}$ & $7.4 \times 10^{2} \mathrm{~b}$ & $3.1 \times 10^{1}-5.5 \times 10^{2}$ & $2.2 \times 10^{2} \mathrm{~b}$ \\
\hline & & SAF & $2.5 \times 10^{1}-3.2 \times 10^{2}$ & $1.5 \times 10^{2} \mathrm{a}$ & $<1.0 \times 10^{0}-3.4 \times 10^{0}$ & $<1.0 \times 10^{0}$ \\
\hline
\end{tabular}

$\mathrm{a}, \mathrm{b}$, and $\mathrm{c}$ homogeneous subsets on the basis of Tukey test

resistant enterococci, which were not removed with significantly lower rates than heterotrophs $(p \leq 0.001)$. In summary, the plant with longer hydraulic residence time (SAF) presented higher removal rates and homogeneity, i.e., different bacterial groups and resistance phenotypes were removed similarly, whereas the opposite was observed for shorter periods of treatment (plant TF). In general, in plant TF, facultative anaerobes of fecal origin, as the enterobacteria and enterococci, were removed more efficiently than total heterotrophs (Fig. 2 and Table 4).

Treated wastewater: effect of the plant size and bacterial removal rates

The values of CFU per milliliter discharged differed significantly among the three plants examined is this study 


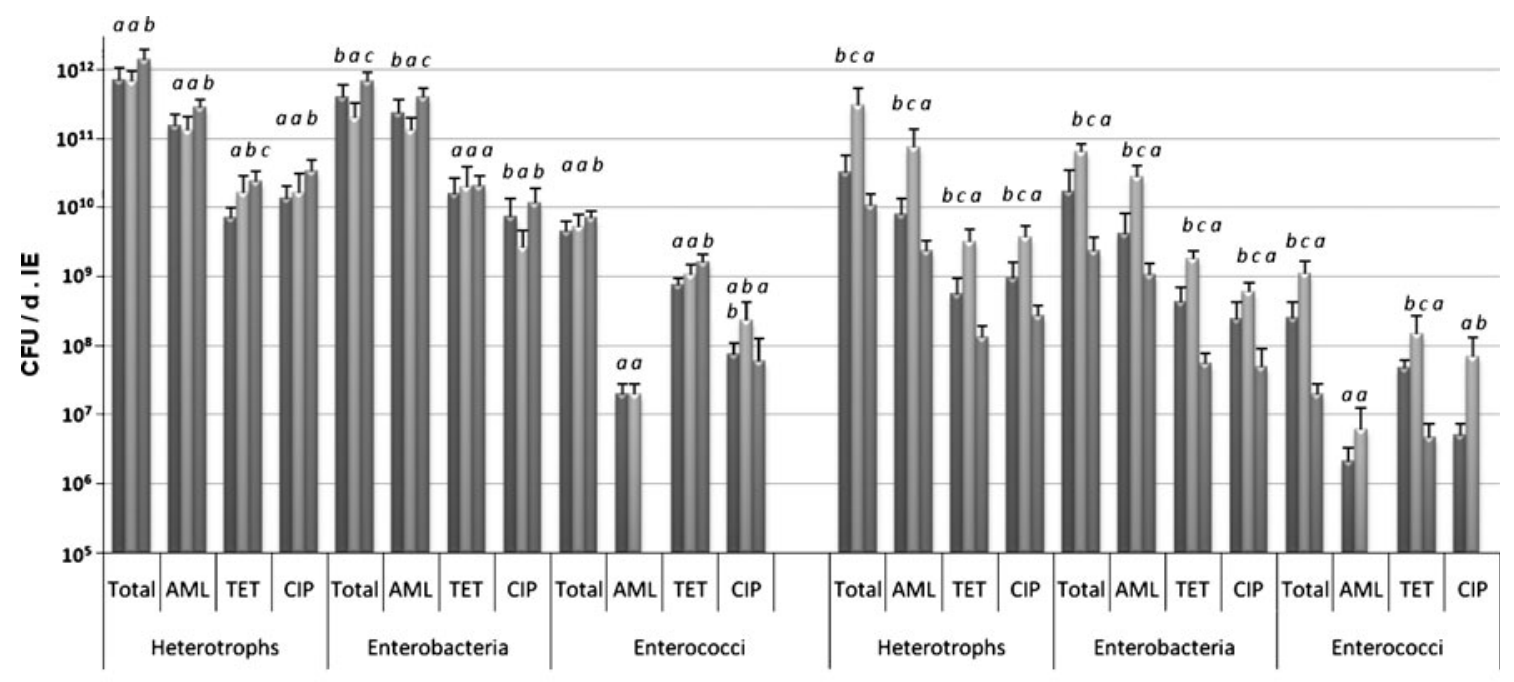

Raw Wastewater

口. AS

Fig. 1 Colony forming units per day and per inhabitant equivalent (IE) of total and antibiotic-resistant heterotrophic bacteria, enterobacteria, and enterococci in the raw and treated wastewater. a-c The

and could be ranked as TF $>$ AS $>$ SAF $(p \leq 0.001)$, independently of the bacterial group or antibiotic tested (Table 2). When the analysis was based on the abundance of CFU per inhabitant equivalents, a similar pattern was observed (Fig. 1). The ranking of bacterial load, both in terms of density (CFU per milliliter) or abundance (CFU per inhabitant equivalents), had no consequences on the percentages of antibiotic-resistant bacteria in the treated effluent (Table 3). For heterotrophic bacteria, the percentages of antibiotic-resistant bacteria in the treated effluent were similar in the three plants, except for ciprofloxacin, with significantly lower resistance prevalence in plant TF $(p<0.05)$. For enterobacteria, amoxicillin resistance was less prevalent in plant AS effluent than in the other plants $(p \leq 0.001)$, whereas ciprofloxacin resistance was higher in SAF treated wastewater $(p<0.05)$. For enterococci, the low counts of antibiotic-resistant bacteria in the treated effluent of plant SAF hampered the comparison for amoxicillin and ciprofloxacin resistance. Nevertheless, it was observed that among the enterococci, ciprofloxacin resistance was more prevalent in the effluent of the plant TF than on that of AS $(p \leq 0.001)$.

The comparison of the antibiotic resistance prevalence in the raw wastewater with that discharged in the treated effluent evidenced some significant variations occurring after wastewater treatment ( $p$ values in Table 3). In plant AS, ciprofloxacin-resistant enterococci were significantly more prevalent in the treated effluent $(p<0.05)$ than in the raw wastewater. In turn, an apparent general significant decrease of amoxicillin-resistant enterobacteria in the treated effluent $(p \leq 0.001)$ was attributed to an exception- ally high prevalence of resistance in the inflow in a single sampling campaign. In average, in plant $\mathrm{TF}$, wastewater treatment implied a significant reduction of the percentage of tetracycline-resistant organisms in all bacterial groups $(p \leq 0.01)$. In plant SAF, the percentage of heterotrophic bacteria with tetracycline resistance suffered a reduction after wastewater treatment $(p<0.05)$.

\section{Discussion}

The objective of this work was to study some factors influencing the burden of municipal wastewater treatment plants on the spreading of antibiotic-resistant bacteria. The density of bacteria (expressed in terms of CFU per milliliter) belonging to different groups observed in the present study were in the same order of magnitude as those reported in previous publications for different geographic regions and types of wastewater treatment plants (Guardabassi et al. 2002; Reinthaler et al. 2003; Vilanova et al. 2002; Blanch et al. 2003; Servais and Passerat 2009). One of the major achievements expected from a wastewater treatment plant is the elimination of bacteria present in sewage. Removal values ranging 1.5-2 $\log$ units have been reported for different municipal wastewater treatment plants, namely, comprehending tertiary treatment (Guardabassi et al. 2002; Vilanova et al. 2002; Blanch et al. 2003; Reinthaler et al. 2003). These values are in the same range as we observed for plant SAF, are slightly higher than those determined for plant AS, and put in evidence the poor efficiency of plant TF. In fact, plant TF presented very low bacterial removal rates, 
although contributed to significant reductions on antibiotic resistance percentages. In contrast, SAF was the most efficient plant on bacterial removal, although, except for tetracycline-resistant heterotrophs, did not produce final effluents with lower antibiotic resistance percentages. The high bacterial removal rates observed in plant SAF were associated with a remarkable stability of this plant, with all bacterial groups being removed with rates up to $>99 \%$. Such stability facilitates the implementation of regular monitoring schemes aiming the prediction of the final effluent quality, in terms of both total and antibiotic-resistant bacteria. In contrast, plant $\mathrm{TF}$, which uses a TF, was very unstable with highly heterogeneous rates of removal for different bacterial groups, hampering the monitoring schemes and limiting any predictive assessment of the final effluent. Besides the biological treatment used, the hydraulic residence time has, in this respect, a determinant influence. In contrast with the short period used in plant TF, in which the passage through the TF takes only $30 \mathrm{~min}$, in SAF, wastewater resides for $24 \mathrm{~h}$ in the plant, contributing to the homogenization of the bacterial populations, and thus to the stability observed. Vilanova et al. (2002) observed a similar homogeneity in an AS plant with residence times of $24 \mathrm{~h}$. In turn, the variability reported in plant TF may be due to both the low hydraulic residence time and the fact that in percolating bioreactors the detachment of biomass aggregates is often observed leading to the heterogeneity observed.

The comparison of the raw wastewater among the three plants examined indicated the bacterial density (CFU per milliliter) was similar in the three, whereas bacterial abundance per inhabitant equivalent was higher in the plant SAF. This pattern was not observed in the treated wastewater, where the consistent ranking on the basis of plant size or bacterial removal efficiency was possible. Such a ranking was coherent for the different bacterial and antibiotic resistance groups under study. The homogeneity of the enumeration values and diversity and population structure in the treated effluent, independently of the inflow properties, has been referred before (Vilanova et al. 2002; Blanch et al. 2003; Manaia et al. 2010). This observation suggests that the treated effluent composition, rather than depending on the inflow characteristics, will be strongly influenced by several aspects inherent to each treatment plant, such as the biological process, hydraulic residence time, bacterial removal rates, and inflow volume.

Some questions, raised at the beginning of this study, are discussed below. One of such questions was whether certain characteristics of the raw inflow (size of the population and/or volume of inflow, the reception of pretreated industrial or hospital effluents) could influence the levels of antibiotic-resistant organisms reaching a municipal wastewater treatment plant. Whenever significant differences of the counts of CFU per capita (inhabitant equivalent) were observed, it was in plant SAF with higher 
Fig. 2 Bacterial removal rates observed for the different bacterial taxonomic and antibiotic resistance groups

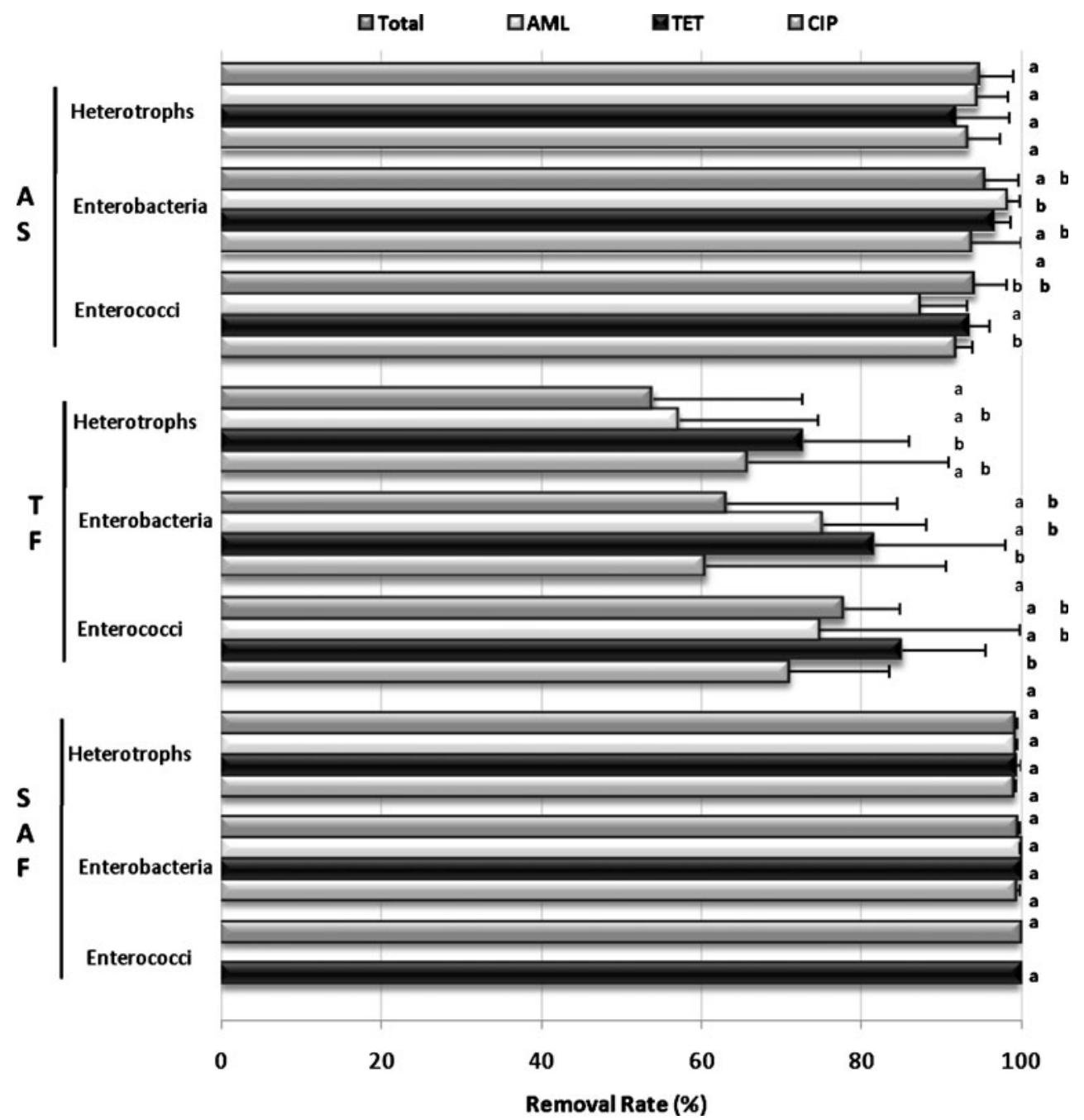

Removal Rate (\%) bacterial loads per inhabitant equivalent, although this inflow did not evidence higher density (CFU per milliliter) of bacteria. Given inhabitant equivalents are calculated on the basis of the organic biodegradable load of the inflow, a likely explanation for this observation is that SAF may receive, in average, sewage with a lower organic load than the other two plants included in this study. This explanation is supported by the description of the touristic coastal agglomeration area where this facility is located, with less industrial and quotidian urban activity. It is also noteworthy
Table 4 Average bacterial removal rates for the different bacterial taxonomic and antibiotic resistance groups in each treatment plant

$\begin{array}{lllll}\text { Resistance group } & \text { WWTP } & \text { Heterotrophs } & \text { Enterobacteria } & \text { Enterococci } \\ \text { Total } & \text { AS } & 94.9 \mathrm{a} & 95.6 \mathrm{a} & 94.2 \mathrm{a} \\ & \text { TF } & 53.9 \mathrm{a} & 63.3 \mathrm{a} & 77.9 \mathrm{~b} \\ & \text { SAF } & 99.2 \mathrm{a} & 99.6 \mathrm{~b} & 99.7 \mathrm{~b} \\ \text { AML } & \text { AS } & 94.6 \mathrm{~b} & 98.3 \mathrm{c} & 87.3 \mathrm{a} \\ & \text { TF } & 57.2 \mathrm{a} & 75.3 \mathrm{a} & 74.8 \mathrm{a} \\ & \text { SAF } & 99.2 \mathrm{a} & 99.7 \mathrm{~b} & \\ \text { TET } & \text { AS } & 91.8 \mathrm{a} & 96.7 \mathrm{~b} & 93.5 \mathrm{a}, \mathrm{b} \\ & \text { TF } & 72.8 \mathrm{a} & 81.7 \mathrm{a}, \mathrm{b} & 85.1 \mathrm{~b} \\ & \text { SAF } & 99.4 \mathrm{a} & 99.7 \mathrm{a} & 99.7 \mathrm{a} \\ \text { CIP } & \text { AS } & 93.4 \mathrm{a} & 93.8 \mathrm{a} & 91.7 \mathrm{a} \\ & \text { TF } & 65.8 \mathrm{a} & 60.6 \mathrm{a} & 71.0 \mathrm{a} \\ & \text { SAF } & 99.2 \mathrm{a}, \mathrm{b} & 99.5 \mathrm{~b} & 98.9 \mathrm{a}\end{array}$

$\mathrm{a}, \mathrm{b}$, and c, homogeneous subsets on the basis of Tukey test for the different bacterial groups within each wastewater treatment plant and antibiotic resistance group 
that it was for this plant that the discrepancy between agglomeration population and inhabitant equivalents was more accentuated. Nevertheless, the possible reduced organic load of the sewage of this plant did not imply lower density inputs of antibiotic-resistant bacteria. In fact, the density (CFU per milliliter) of antibiotic-resistant bacteria in the raw inflow of SAF was not significantly different from that observed in the plants receiving industrial or hospital effluents (AS and TF). Additionally, in general, no significant differences between these two plants were observed in terms of antibiotic-resistant bacteria counts (CFU per milliliter or CFU/inhabitant equivalent). The pretreated industrial effluents received by plant AS comprise tinctures, textile, small farms, and pharmaceuticals, whereas in plant TF are discharged pretreated effluents of a hospital with around 1,200 beds and an area of $114.000 \mathrm{~m}^{2}$. In either case, the results suggest that pretreatment, applied before the discharge to the municipal collector, may attenuate significantly the spreading of bacteria with antimicrobial resistance. Nevertheless, it should be emphasized that plant TF receives only $15 \%$ of hospital effluents. Although Kümmerer (2009b) referred similar levels of antibioticresistant bacteria in hospital and municipal wastewaters, different authors have reported higher rates of resistance in hospital effluents (Blanch et al. 2003; Servais and Passerat 2009). In summary, our results give support to the recommendation that even not being a legal requirement, the pretreatment of hospital effluents should be strongly encouraged by authorities and policy makers.

Another issue addressed in this study was whether in the same plant bacteria belonging to different taxonomic and antibiotic resistance groups were removed at similar rates. Three bacterial groups, heterotrophs, enterobacteria, and enterococci, were included in this study. Wastewater heterotrophs comprise mainly bacteria such as Pseudomonas aeruginosa and other pseudomonads, Acinetobacter, aeromonads, and a minority of enterobacteria non-Escherichia coli (our data, unpublished). These organisms are fastgrowing bacteria with recognized adaptability potential and important vectors of antibiotic resistance (McGowan 2006). In spite of this, and probably due to the heterogeneity of bacteria growing on PCA, antibiotic resistance in heterotrophs from raw wastewater was lower than in the other groups examined (Table 3). In the current study, enterobacteria, given the selective medium used, comprise mainly E. coli, an indicator of fecal contamination, and one of the most studied vectors of antibiotic resistance (Paterson 2006; Ferreira da Silva et al. 2007). As reported by previous authors, we observed high levels of beta-lactam resistance in this bacterial group (Paterson 2006; Ferreira da Silva et al. 2007) and lower to tetracyclines and fluoroquinolones. Comparing both populations, heterotrophs and enterobacteria, it was observed that in general, culturable heterotrophs presented lower reduction rates than enterobacteria, hinting the above-mentioned good fitness of those organisms. These results suggest that heterotrophs, more than enterobacteria, may be relevant vectors of antibiotic resistance in wastewater treatment plants. According to previous studies, wastewater enterococci comprise mainly the species Enterococcus faecalis, Enterococcus faecium, and Enterococcus hirae (Blanch et al. 2003; Ferreira da Silva et al. 2006). These Gram-positive cocci have slower growth and are less abundant than the enterobacteria and heterotrophs examined in this study. Enterococci evidenced very low rates of resistance to betalactams but high resistance prevalence to tetracycline, a finding that is in agreement with previous studies (Costa et al. 2006; Ferreira da Silva et al. 2006). The homogeneity on the removal of bacteria, independently of the taxonomic or antibiotic resistance group, was observed to depend mainly on the stability of the treatment plant, with longer hydraulic residence times favoring the elimination of more bacteria of different groups. This was exemplified by plant SAF (Table 4 and Fig. 2). Plant TF represented the opposite of SAF, with tetracycline-resistant bacteria, independently of the group, being removed with higher efficiency than the others (Fig. 2). The data obtained in this study does not allow the advancing of possible explanations for this observation, but evidence that in plants with poor removal rates, the removal of a specific antibiotic-resistant organism cannot be inferred from total bacterial removal rates.

The third issue addressed in this study was the comparison of the removal of antibiotic-resistant bacteria and assess if the loads of these bacteria in the treated outflow are directly proportional to those in the raw wastewater and/or bacterial removal rates. The hydraulic residence time was observed to be determinant on the bacterial removal rates and on the consequent microbiological quality of the treated effluent. Nevertheless, higher wastewater treatment efficiency may not imply significant decreases on antibiotics resistance percentages in the treated outflow (Table 3).

In conclusion, it was observed that the microbiological quality of the treated effluent, in terms of predictability of the antibiotic resistance rates and homogeneity of the removal of organisms belonging to different resistance groups is strongly influenced by the treatment efficiency. However, in average, higher bacterial removal rates, associated with longer hydraulic residence times, do not contribute to significant reductions on the prevalence of antibiotic-resistant bacteria in the final effluent.

Acknowledgements The authors gratefully acknowledge the engineers of the wastewater treatment facilities for their support for samples collection and the $\mathrm{COD}$ and $\mathrm{BOD}_{5}$ analyses and the technicians of the Portuguese Environment Agency for heavy metals determinations. This study was financed by Fundação para a Ciência e a Tecnologia (project PTDC/AMB/71236/2006). 


\section{References}

Baquero F, Martínez JL, Cantón R (2008) Antibiotics and antibiotic resistance in water environments. Curr Opin Biotechnol 19:260 265

Blanch AR, Caplin JL, Iversen A, Kühn I, Manero A, Taylor HD, Vilanova X (2003) Comparison of enterococcal population related to urban and hospital wastewater in various climatic and geographic European regions. J Appl Microbiol 94:994-1002

Costa PM, Vaz-Pires P, Bernardo F (2006) Council Directive 91/271/ EEC, of 21 May 1991 concerning urban waste-water treatment. Antimicrobial resistance in Enterococcus spp. isolated in inflow, effluent and sludge from municipal sewage water treatments. Water Res 40:1735-1740

Ferreira da Silva M, Tiago I, Veríssimo A, Boaventura RAR, Nunes OC, Manaia CM (2006) Antibiotic resistance of enterococci and related bacteria in an urban wastewater treatment plant. FEMS Microbiol Ecol 55:322-329

Ferreira da Silva M, Vaz-Moreira I, Gonzalez-Pajuelo M, Nunes OC, Manaia CM (2007) Antimicrobial resistance patterns in Enterobacteriaceae isolated from an urban wastewater treatment plant. FEMS Microbiol Ecol 60:166-176

Forster S, Lappin-Scott HM, Snape JR, Porter J (2003) Rains, drains and active strains: towards online assessment of wastewater bacterial communities. J Microbiol Methods 55:859-864

Gallert C, Fund K, Winter J (2005) Antibiotic resistance of bacteria in raw and biologically treated sewage and in groundwater below leaking sewers. Appl Microbiol Biotechnol 69:106-112

Goñi-Urriza M, Capdepuy M, Arpin C, Raymond N, Caumette P, Quentin C (2000) Impact of an urban effluent on antibiotic resistance of riverine Enterobacteriaceae and Aeromonas spp. Appl Environ Microbiol 66:125-132

Guardabassi L, Lo Fo Wong DMA, Dalsgaard A (2002) The effects of tertiary wastewater treatment on the prevalence of antimicrobial resistant bacteria. Water Res 36:1955-1964
Kim S, Aga DS (2007) Potential ecological and human health impacts of antibiotics and antibiotic-resistant bacteria from wastewater treatment plants. J Toxicol Environ Health B 10:559-573

Kümmerer K (2009a) Antibiotics in the aquatic environment-a review-part II. Chemosphere 75:435-441

Kümmerer K (2009b) Antibiotics in the aquatic environment-a review-part I. Chemosphere 75:417-434

Manaia CM, Novo A, Coelho B, Nunes OC (2010) Ciprofloxacin resistance in domestic wastewater treatment plants. Water Air Soil Pollut 208:335-343

Martínez JL (2009) Environmental pollution by antibiotics and by antibiotic resistance determinants. Environ Pollut 157:2893-2902

McGowan JE Jr (2006) Resistance in nonfermenting gram-negative bacteria: multidrug resistance to the maximum. Am J Med 119 (6A):S29-S36

Observatório Nacional de Saúde (2002) Médicos Sentinela (ONSA). http://www.onsa.pt

Paterson DL (2006) Resistance in Gram-negative: Enterobacteriaceae. Am J Med 119(6A):S20-S28

Reinthaler FF, Posch J, Feierl G, Wüst G, Haas D, Ruckenbauer G, Mascher F, Marth E (2003) Antibiotic resistance of E. coli in sewage and sludge. Water Res 37:1685-1690

Servais P, Passerat J (2009) Antimicrobial resistance of fecal bacteria in waters of Seine river watershed (France). Sci Total Environ 408:365-372

Tchobanoglous G, Burton FL, Stensel HD (2003) Wastewater Engineering: Treatment and Reuse, 4th edn. Metcalf \& Eddy, Inc, McGraw-Hill, New York

Vilanova X, Manero A, Cerdá-Cuéllar M, Blanch AR (2002) The effect of a sewage treatment plant effluent on the faecal coliforms and enterococci populations of the reception river. J Appl Microbiol 92:210-214

Watkinson AJ, Micalizzi GB, Bates JB, Costanzo SD (2007) Novel method for rapid assessment of antibiotic resistance in Escherichia coli isolates from environmental waters by use of a modified chromogenic agar. Appl Environ Microbiol 7:2224-2229 